\title{
Food Supply Chains as Cyber-Physical Systems: a Path for More Sustainable Personalized Nutrition
}

\author{
Sergiy Smetana ${ }^{1}$ (D) $\cdot$ Kemal Aganovic $^{1} \cdot$ Volker Heinz $^{1}$ \\ Received: 10 January 2020 / Accepted: 24 July 2020 / Published online: 22 August 2020 \\ (C) The Author(s) 2020
}

\begin{abstract}
Current food system evolved in a great degree because of the development of processing and food engineering technologies: people learned to bake bread long before the advent of agriculture; salting and smoking supported nomad lifestyles; canning allowed for longer military marches; etc. Food processing technologies went through evolution and significant optimization and currently rely on minor fraction of energy comparing with initial prototypes. Emerging processing technologies (high-pressure, pulsed electric fields, ohmic heating, ultrasound) and novel food systems (cultured biomass, 3-D bioprinting, cyber-physical chains) try to challenge the existing chains by developing potentially more nutritious and sustainable food solutions. However, new food systems rely on low technology readiness levels and estimation of their potential future benefits or drawbacks is a complex task mostly due to the lack of integrated data. The research is aimed for the development of conceptual guidelines of food production system structuring as cyber-physical systems. The study indicates that cyber-physical nature of modern food is a key for the engineering of more nutritious and sustainable paths for novel food systems. Implementation of machine learning methods for the collection, integration, and analysis of data associated with biomass production and processing on different levels from molecular to global, leads to the precise analysis of food systems and estimation of upscaling benefits, as well as possible negative rebound effects associated with societal attitude. Moreover, such data-integrated assessment systems allow transparency of chains, integration of nutritional and environmental properties, and construction of personalized nutrition technologies.
\end{abstract}

Keywords Cyber-physical systems $\cdot$ Food chains $\cdot$ Food systems $\cdot$ Traceability $\cdot$ Sustainability

\section{Introduction}

Food processing technologies not only influenced our lifestyle making it more comfortable and relaxed, but also became a major evolutionary force for the development of food systems and humans within it. People learned to bake bread long before the advent of agriculture; salting and smoking supported nomad lifestyles; canning allowed for longer military marches; etc. [2]. Since their invention, certain modern food processing technologies underwent long evolution and significant equipment and process optimization, exhibiting high efficiency levels compared with their initial prototypes. However, current demands for "unprocessed" or minimally processed, "clean label", and "functional" foods call for

Sergiy Smetana

s.smetana@dil-ev.de

1 German Institute of Food Technologies (DIL e.V.), Quakenbrück, Germany changes in how the food is produced and processed, where novel processing technologies and novel food systems could respond to these demands $[11,86,91]$. Emerging processing technologies often rely on other sources of energy such as mechanical, electrical, electro-magnetic, or others, compared with conventional ones using mostly thermal energy. New technologies based on application of high-pressure (static high pressure, high pressure homogenization, supercritical fluids, shockwave), electrical energy (pulsed electric fields, ohmic heating), or using electromagnetic radiation (radiofrequency, microwave, E-beam) and novel food systems (cultured biomass, 3-d bioprinting, cyber-physical chains) try to challenge the existing chains by developing potentially more nutritious and sustainable food solutions.

However, as many innovations in general, novel developments in food systems often rely on low technology readiness levels (TRL). While low TRL technologies are suitable for small-scale developments and generation of added value, they create additional challenges for the estimation of future potential benefits or drawbacks. It is becoming a complex task, mostly due to the lack of integrated data and multifaceted 
nature of food systems. In order to deal with complex data issues, developed data solutions should be applied. However, such solutions are not adapted to the specific requirements of food production and consumption due to enormous biological variations and unsuitable data acquisition [36, 82]. At the same time, food system can be foreseen as a cyber-physical system (CPS), able to reach the highest autonomy levels for self-management and self-control, but it requires special approaches and development of a framework applicable for further development of cyber and physical solutions.

This review aims for the development of conceptual guidelines of food production system structuring as cyber-physical systems. The article is structured to comprehensively review current literature dealing with improvement of food production-consumption chains perceiving them as potential cyber-physical systems, suitable for automated traceability, sustainability assessment and personalized nutrition. It starts with explaining and illustrating the concepts of cyber-physical systems (CPS) and current knowledge on CPS application in food industry. Further, the paper addresses definition of conceptual requirements for food production systems transformation into CPS, followed by requirements of food system digitalization, emerging processing technologies, traceability approaches, and personalized retail and nutrition. It is finalized with an overview on potential benefits and negative consequences of food systems transformation into CPS while applying the conceptual guidelines.

\section{The Concepts of Cyber-Physical Systems (CPSs)}

The definition of cyber-physical systems (CPSs) has emerged in the new millennium as a response to the need of developing conceptual and efficient framework dealing with constantly increasing interactions between cyber computational systems and physical hardware. CPSs therefore are defined as transformative technologies for managing interconnected systems between its physical assets and computational capabilities [8]. CPS can also be considered in more cyber domain as "a computational operation with the surrounding physical object across downstream/upstream industry in collaboration environment" [25]. This highlights a rather virtual character of the CPS. While "classical" definition describes CPS as integrated computation and physical processes or embedded computational systems and their physical environment $[23,61,68$, 75], some authors highlight the leading role for the computation core, which coordinates, operates, and monitors physical, biological, and engineered systems $[8,75,90]$. The whole variety of definitions and concepts can be arranged in 4 main groups according to the main fields of application: (1) control theory (CPSs are understood as a composition of the physical world, transducers, and control components), (2) computer sciences (CPSs are understood as a composition of the physical world, transducers, control components, and computer sciences elements), (3) communication engineering (CPSs are understood as a combination of transducers, control components, some data analytics elements, computer science elements, and communication components), and (4) vertical systems (CPSs are understood as a combination of all the components: physical world, transducers, control components, data analytics elements, computation elements, communication components) [16]. Despite a great variety of definitions and concepts, they all acknowledge that through the connection to the advanced computational technologies, CPS can provide autonomous predictive management, self-diagnosis/maintenance mechanism for risk avoidance, and collaborative production planning for improved performance. CPSs, therefore, have all the required properties for the application in food industry for improvement of food production safety or traceability [25].

Even though there are a lot of CPS concepts and definitions, they still undergo intense evolution process. Constantly changing properties of both, physical and cyber parts, pose difficulties for the design of "smart networks", which previously were never dealt with $[3,19,68]$. For the last 20 years physical hardware system went through accelerated developments [126], which resulted in higher availability and affordability of sensors, data storage systems, and interconnected wired and wireless systems. Such developments in its turn resulted in continuous generation of high data volumes, which received the name "Big Data" [31, 67, 87, 95, 97, 113]. CPS in such environment evolved into frameworks dealing with management of Big Data for interconnected hardwaresoftware networks aiming to leverage intelligent, resilient, and self-adaptable machines capable to deal with complex physical world interactions [77]. CPS got a high level of implementation in industrial environment forcing the development and emergence of smart factories ("industry 4.0") and "digital twins" [18, 103]. While CPS can be declared as a conceptual system describing "industry 4.0" and "digital twins" [88, 107], it goes beyond their scope of functioning and implementation $[104,107]$. It can be applied to more diverse and extended systems beyond industrial environment.

There are plenty of concepts and definitions like embedded systems, legacy systems, industry 4.0, pervasive sensing, machine-to-machine communications, etc., related in higher or lower degree to CPS concept $[16,32,68]$. If most of the definitions can be differentiated from CPS, "Internet-ofthings" (IoT) is a concept, which has a lot of similar characteristics to CPS [16]. This review supports the view that CPS belongs to IoT, in a way that the CPS is only a new pattern or a scenario of IoT $[16,76,121]$. For example, the aggregated definition of Monostori et al. [76] highlights very well the integration of CPS with Internet, pointing towards reliance of CPS systems on data-processing services available on the Internet. Such interconnection and integration could have positive and negative consequences for CPS concept applied in food industry (see next chapter). 
CPSs have been long recognized as an intelligent autonomous system going through learning human behaviours with the help of artificial intelligence [12]. At the same time, intelligent autonomous cyber system requires development of extensive and advanced physical architecture-based information system [25]. The Eindhoven Institute for Research on ICT (EIRCT) identified six components of CPS architecture: physical world, transducers, control components, data analytics elements, computation elements, and communication components $[16,33]$. Physical part of CPS in such grouping is limited to physical world and transducers; however, some authors separate physical world (devices or hardware) and physical environment (environment where the physical objects are located) $[46,61]$. Cyber part, on the other hand, is quite well conceptualized into 5-level CPS structure [68], which provides a guideline for developing and deploying a CPS for manufacturing application. The $5 \mathrm{C}$ architecture connects functional levels with specific hierarchical implementation conditions from physical to higher cognition: (1) Smart Connection Level, aimed for condition based monitoring through physical sensors; (2) Data-to-Information Conversion Level, for self-aware prognostics and health management; (3) Cyber Level, for peer to peer monitoring, selfcomparison, and twin modelling; (4) Cognition Level for decision support system allowing integration of simulation and synthesis, and collaborative diagnostics and decision-making; and (5) Cognition Level for resilient control system and selffunctions including avoidance of error actions [68]. Such well-structured architecture allows for the guided design of CPS, especially in the cyber part of it. Physical part of CPS, especially in application to food systems, remains so far poorly covered.

\section{Current Knowledge on CPS Application in Food Industry}

Despite quite a long history [12], in many cases, CPSs are still in the early stages of development, with successful constantly working cases of application in a few areas (Fig. 1). The following main application fields of CPS were identified by the CPS Vision Statement issued by the federal Networking and Information Technology Research and Development (NITRD) CPS Senior Steering Group [76, 80]:

- Agriculture

- Building controls

- Defence

- Energy response

- Energy

- Healthcare

- Manufacturing and industry

- Society

- Transportation
Such list is rather interesting as it devotes a huge attention to energy and different forms of manufacture, which partially corresponds to the application areas set by the authors from Berkley University (Fig. 1). The last source [76], however, indicates a wider range of applications including communication, robotics as a separate industry, and physical security (as a quite wide CPS systems devoted for automated safety surveillance). Food is not precisely mentioned by either of the classifications. Potentially it relates to the huge complexity of food systems [6, 100], which cannot be easily complemented with CPS systems of one area. Food systems in their wide meaning (from biomass production to food consumption, and beyond) require implementation of CPS from diverse application areas starting from manufacture, over agriculture and aquaculture, including consumer and communication (Fig. 1).

As the literature often does not distinguish the CPS application for food systems, it is necessary to review the compliant options of CPS integration from other fields. For example, certain similarities and transfer points can be drawn from medical and agricultural CPS. Medical CPS systems are quite well developed with multiple examples. They can be aggregated into few main application groups: notable (records); daily use; medical status monitoring; medication intake control; and emerging group (e-health architecture, cloud computing solutions, CPS modelling for medical processes validation, smart living, etc.) [49].

Agriculture CPS lately got quite well researched in the topic of smart agriculture in the development of CPS systems [4, 28]. Precision agriculture is playing a major role to enhance the efficiency and resource savings [65, 89]. Precision agriculture can rely on quite specific developments such as Wireless Underground Sensor Networks, when machinery is "communicated" with sensors under soil $[96,112]$ or underground sensor networks controlling the quality of soils [13, 50, 81, 112]. Further developments in agricultural stage include real-time monitoring of crops growth in field and greenhouses [47, 64, 94, 105], weed control [119], and precise autonomous water or fertilizer management on the field $[60,72,93]$ or frost monitoring [125]. Some authors proposed an overall method for information integration based on a service-oriented architecture (SOA) in agri-food supply chain networks, potentially enhanced with cloud systems, [25, 45, 116].

A few concepts of CPS application are proposed to enhance traceability of agricultural food systems [26] or "virtualization" of food supply chains [111]. Application of virtual models of different food systems with known parameters is an immensely popular method to develop smart management systems of food supply chains [25, 110, 111, 114, $120,124]$. Application of such systems in reality is a challenging task [1, 101, 109].

At the same time, food processing is rather poorly covered by the development of CPS systems. Literature indicates a few 
Fig. 1 The concept map of CPS. Source: Berkley University [16]

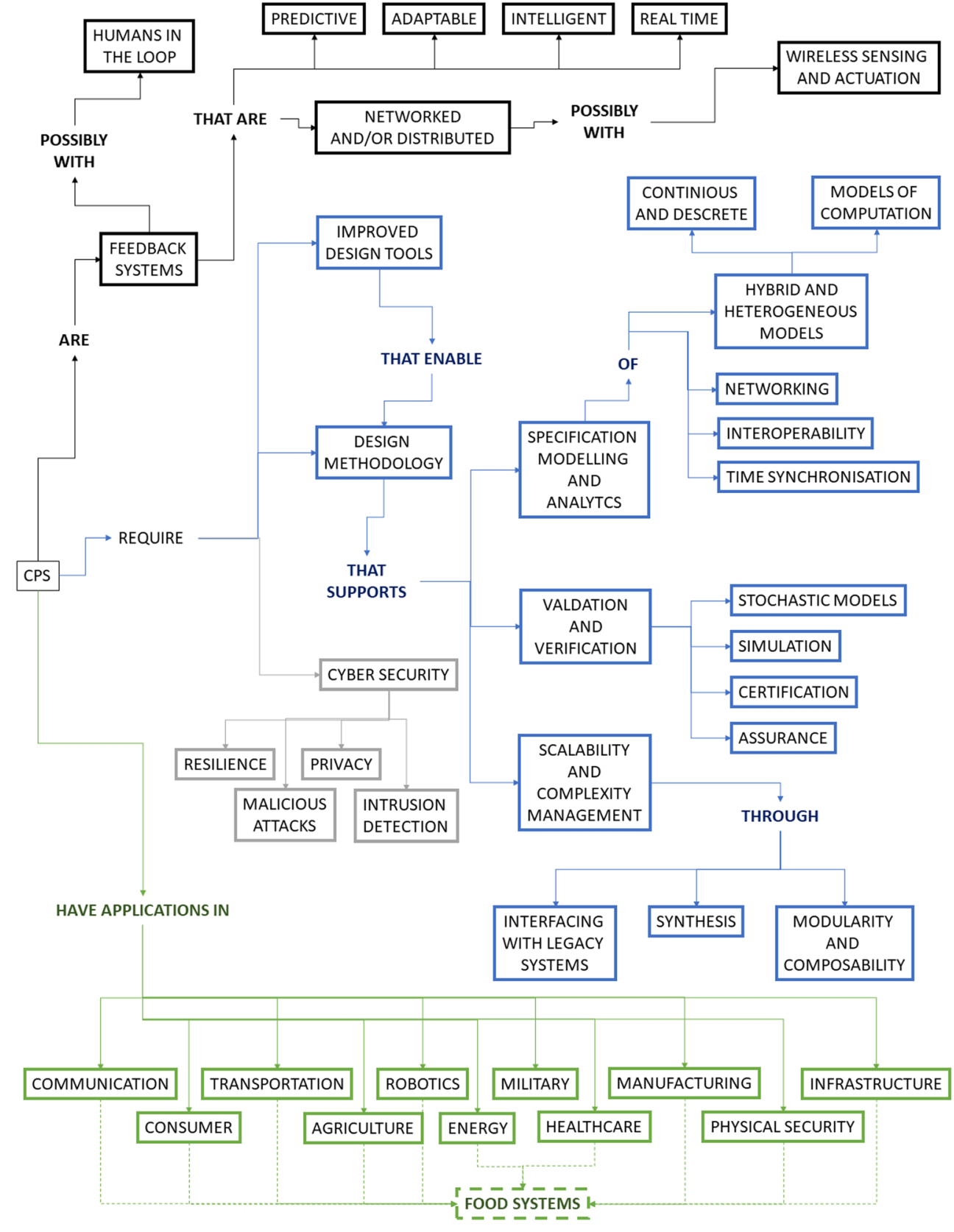

scarce examples, where CPSs are applied in the form of wireless networks for bread manufacturing process optimization [9]; robotics for packaging, picking and placing, pelletizing, inspection, testing, and serving in restaurants [54, 59]. Catering industry is more devoted to the application of smart and collaborative robots [1]. Recent literature also highlights on the potential of digital twins development for the process optimization in agri-food and especially processing factories [109]. However, first complete agri-food applications of digital twins and smart collaborative robotic networks are ought to be demonstrated [1, 109]. Existing methods oriented on niche applications of machine learning and modelling approaches are indicated in literature (Table 1).
Machine learning algorithms such as Gaussian process regression [24, 122], support vector machine [38] and nondominated sorting genetic algorithm II [34, 58] are applied in milling industry for cost reduction and energy consumption, through predictive process parameter optimization or for product quality improvements via predicting food processing properties (surface roughness, cutting force, structure deformation). Multi-objective optimization finds also cases of application development for food retail [37], food processing and food engineering [41, 42, 53, 106], and food quality control $[5,44,73]$. However, such application developments are rather sporadic and never get connected through single ICT platforms (not even CPS) due to multiple standards and lack of 
Table 1 Food system functions (technologies) with potential of integration in CPS systems

\begin{tabular}{|c|c|c|}
\hline Food system function or technology & CPS integration model & Source \\
\hline Traceability of agri-food systems & Intuitionistic fuzzy-based case-based reasoning technology & {$[26]$} \\
\hline Agri-food supply chain networks & Service-oriented architecture (SOA) & {$[25,116]$} \\
\hline Precision agriculture & Wireless sensor network & [89] \\
\hline Precision agriculture & Cyber-physical system architecture model & {$[65]$} \\
\hline Precision agriculture & Wireless underground sensor networks & $\begin{array}{l}{[96,112]} \\
{[13,50,81} \\
\quad 112]\end{array}$ \\
\hline $\begin{array}{l}\text { Real-time monitoring of crops growth in field and } \\
\text { greenhouses }\end{array}$ & $\begin{array}{l}\text { Sensor-based network, wireless sensor networks, } \\
\text { monitoring, detecting, and responding-CPS }\end{array}$ & $\begin{array}{l}{[47,64,94,} \\
105]\end{array}$ \\
\hline Weed control & Automated weed mapping and variable-rate herbicide spraying (VRHS) system & [119] \\
\hline $\begin{array}{l}\text { Precise autonomous water and fertilizer } \\
\text { management on the field }\end{array}$ & $\begin{array}{l}\text { Agricultural cyber-physical system for solar photovoltaic water systems and } \\
\text { wireless sensor networks }\end{array}$ & {$[60,72,93]$} \\
\hline Bread manufacturing process optimization & Wireless networks application & [9] \\
\hline $\begin{array}{l}\text { Packaging, picking and placing, } \\
\text { pelletizing, inspection and testing, and serving in } \\
\text { restaurants }\end{array}$ & Robotics & {$[54,59]$} \\
\hline Decision support system in agri-food companies & Mind map and conceptual graph models & {$[21]$} \\
\hline Robotic cooking & Batch Bayesian optimization and robotics & {$[56]$} \\
\hline Drying & Gaussian process regression & {$[24]$} \\
\hline Oil brands identification (food production support) & Support vector machine & {$[38]$} \\
\hline Grinding, sorting & Nondominated sorting genetic algorithm II & {$[34,58]$} \\
\hline Drying & $\begin{array}{l}\text { Optimization based on computational fluid dynamics, } \\
\text { several multiphysics modelling methods (e.g. conjugate modelling), } \\
\text { multiscale modelling, and modelling of material properties }\end{array}$ & {$[35]$} \\
\hline Drying, environmental efficiency & Multi-objective optimization & [92] \\
\hline Product development & Sequential quadratic programming & {$[27]$} \\
\hline Olive oil bleaching & Hybrid artificial neural network-genetic algorithm technique & {$[7]$} \\
\hline Food retailing & Multi-objective optimization & {$[37]$} \\
\hline Food processing and food engineering & Multi-objective optimization & $\begin{array}{c}{[41,42,53,} \\
106]\end{array}$ \\
\hline Food quality control & Multi-objective optimization & {$[5,44,73]$} \\
\hline Food quality and safety & Multi-objective optimization & {$[10]$} \\
\hline Complex agri-food chain issues & $\begin{array}{l}\text { Visualization, interactive learning, } \\
\text { interactions between machine learning systems and human experts }\end{array}$ & {$[82]$} \\
\hline Agri-food chains traceability and transparency & Blockchain & {$[30,43]$} \\
\hline Perishable foods active management & Extended material requirements planning (EMRP) model & {$[15]$} \\
\hline
\end{tabular}

interest from value chain actors for data sharing and infrastructure development [20].

The potential explanation to the low application of CPS in food system can be possibly related to the complexity of CPS construction, which is much more than developing a single robot interaction with a product. It is a comprehensive issue covering all dimensions of the control, sensing, processing, machines, communication, system engineering, and integration [98].

Division of physical component of CPS into physical world and physical environment (Kyoung-Dae [46, 61]) for food industry is of highest importance, as it poses a viable direction for the progression of cyber system interaction not only with hardware but also with food packaging.
Smart kitchens with intelligent appliances like fridges and stoves have a potential to define through packaging not only the amount of food and its safety level (expiration date) $[74,123]$, but also actively promote to the consumer food planning through recipes, which has a potential to reduce food waste $[71,74,85]$. Intelligent packaging therefore is foreseen as an enabling technology for the communication between smart home appliances and other agents of supply chain (consumer, retail, producer, waste treatment facilities, etc.) $[39,57,71,79,108]$. Intelligent and active packaging, interacting with food biomass via "Time Temperature Indicators" or other gas indicators or (bio)sensors can inform about the properties of food, picked up by smart appliances [79]. 
Fig. 2 Decomposition of the automation hierarchy with CPS distributed services, joined through a single network, adapted from literature $[14,76]$

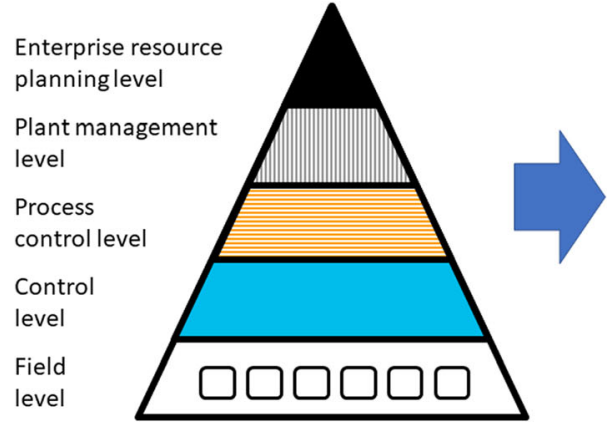

Automation hierarchy

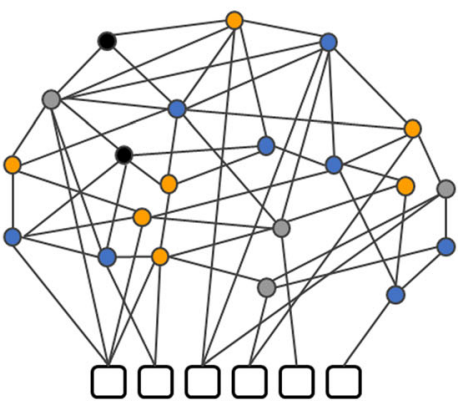

CPS-based automation
However, direct tracking and tracing of food biomass and determination of its properties and ongoing changes require further development of relevant physical tools not only from hardware side, but also from food processing and engineering able to change physical properties of food biomass. Food processing in this case plays a crucial role, as it not only determines the structure and properties of the end product $[55,63]$, but also can efficiently track and trace food structures after relevant hardware and software development.

Interaction between different CPS systems (e.g. transportation, manufacture, communication, consumer, etc.) is adding to the complexity of CPS required for food supply chains. Each of the application areas has developed its unique properties and standards of data exchange for the specific functions, which cannot be easily combined and complemented. Such communication is required for the development of a system of systems for CPS application [117]. Up to now, no smart food chain CPS systems of the higher level are developed.

Application of existing CPS in food systems is also challenging not only due to undeveloped background physical system and higher-level cyber systems, but also due to the only one world network, which can efficiently combine the separate CPS system. Internet is a modern network system with a huge diversity of connected devices, and nodes can play a crucial role for the development and efficient evolution

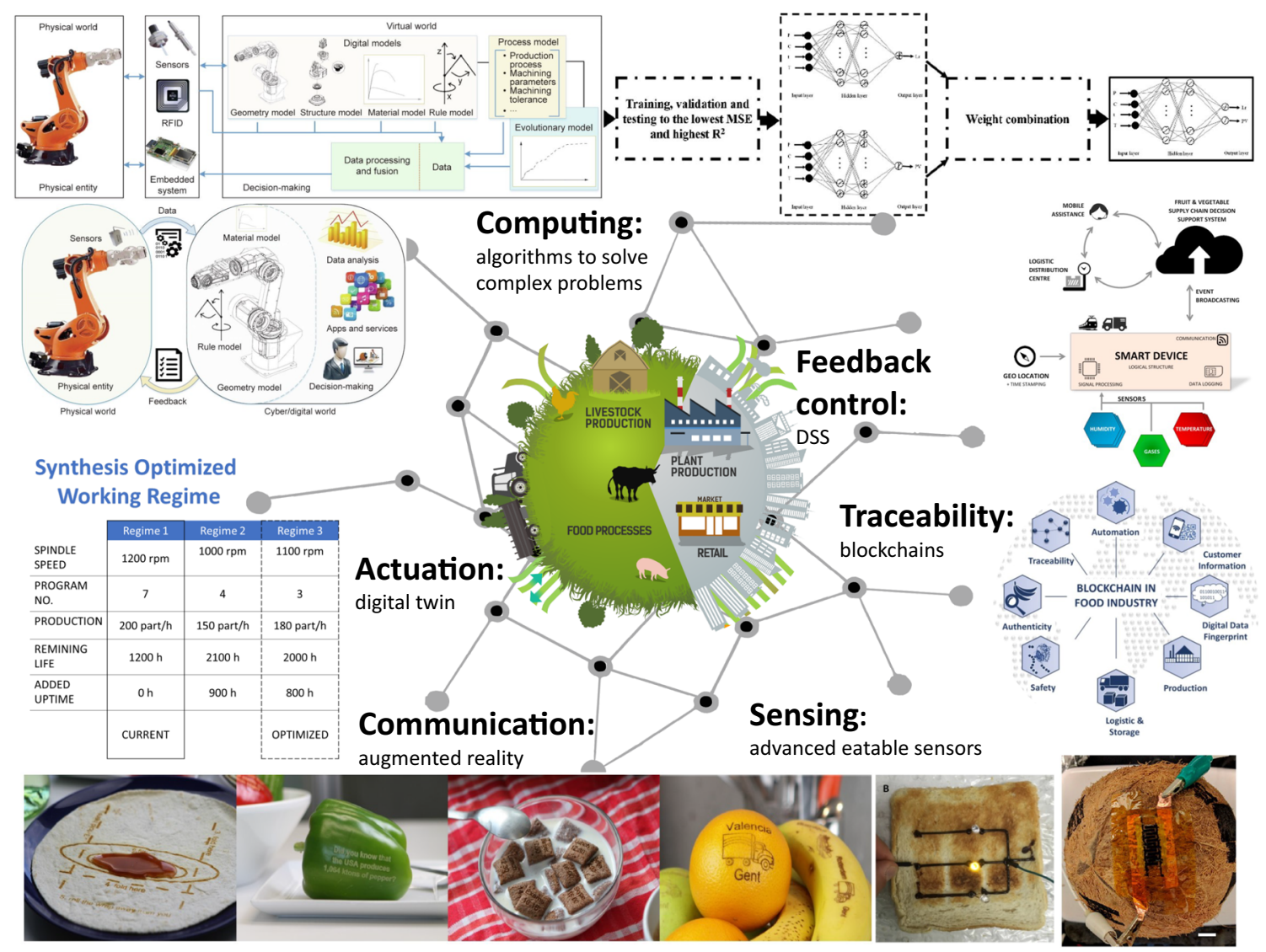

Fig. 3 Overview of approaches, developed to fulfil main functions (in bold) of Food CPS ([7, 15, 29, 30, 48, 51, 68, 102]; http://www.agrocycle.eu/) 
Fig. 4 CPS structure model for food manufacturing: cyber, control, and physical layers (adapted from [59])

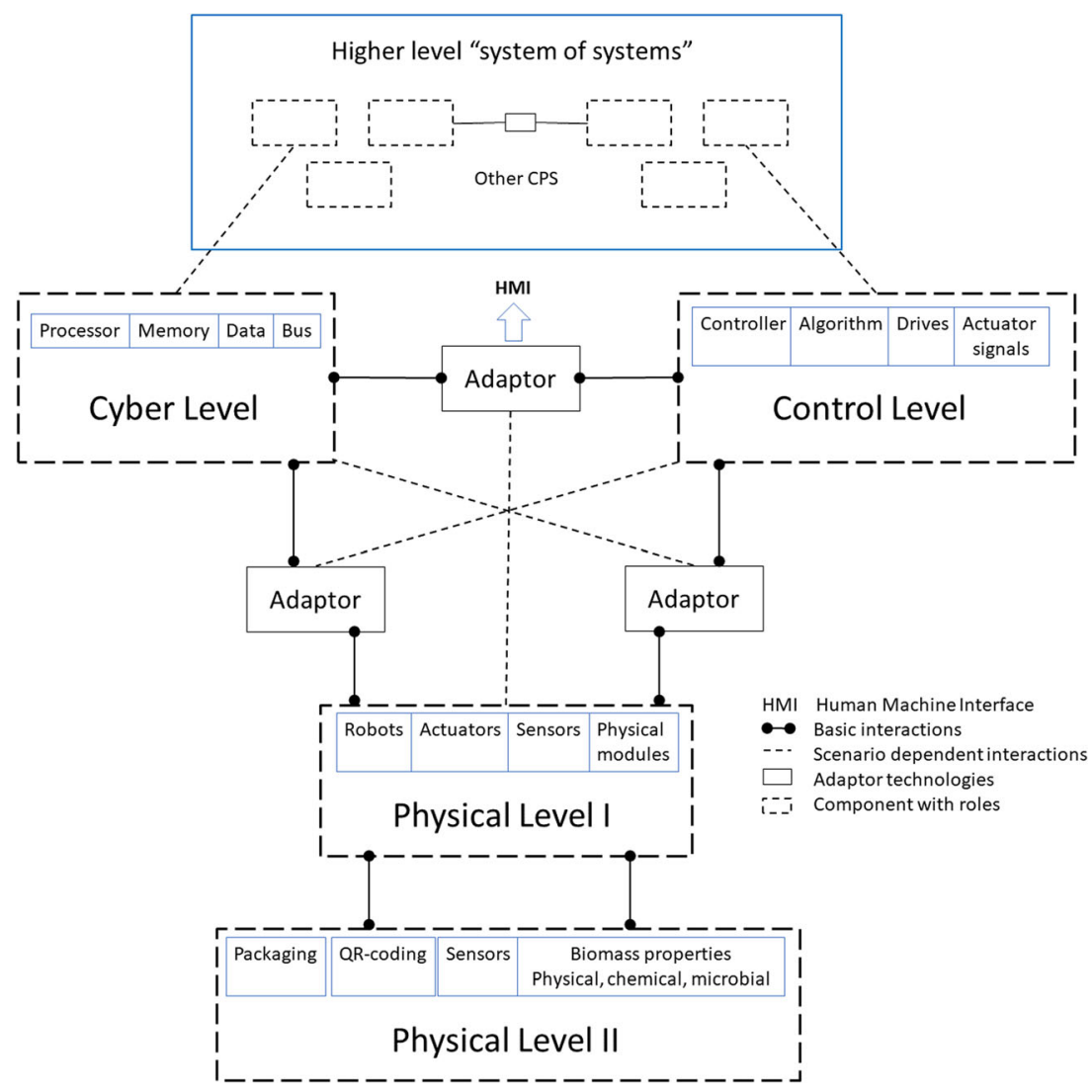

of food chain CPS and its potential automation (Fig. 2). However, reliance on internet comes at a cost. Despite multiple access points to the internet through wired and wireless networks, some areas even in developed countries remain uncovered with either of the access options. Security of connection to the common pull of computational devices can pose serious cyber security risks $[3,22,52]$. Despite the multiple mentioned challenges, there are some perspectives of food CPS developments.

\section{Conceptual Requirements of Food Production Systems Transformation into CPS}

The CPS approach, even though existing for few decades [12], represents still a concept, especially when it is dealing with food system. In 2014, Wright with co-authors grouped application areas of CPS into (1) cyber physical products and assets; (2) cyber physical assembly and manufacturing automation; and (3) cyber physical ecosystems to support the life cycle of the product [117]. The first group is dealing with CPS applied to a single product or technological process such as milling or sorting and has a direct connection to food processing. The second group defines the automation of complex products and systems, and includes concepts of "automation of automation" and "assembly of assemblies" and demonstrates the work on level "system of systems" [78, 84]. It is different from classical food processing automation, because it includes one (or more) hierarchical level of automation, which is not necessarily hierarchically structured (Fig. 2). The third and higher level of CPS integration is demonstrating dealing and tracking of product properties along the life cycle and automated adaptation to the design or manufacturing according to the responses from the lifetime of the product. Such high level cyber-physical ecosystem can collect the data from multiple products in diverse conditions and enable the analysis of data collected for the complete variety of products without giving specific attention to a single product and eliminating minor errors (Fig. 3). CPS at life cycle level (or ecosystem level) can therefore enhance the prediction errors and potential problems associated, for example, with contamination or breakage risks for the complete spectrum of products. Moreover, it can diagnose the reasons for such problems [117]. Such grouping of application areas allows to determine the requirements to food CPS.

Literature indicates two possible areas of application for the development and integration of CPS in food system. The first one (1) reviews the food engineering and manufacturing CPS as an area that has a similar automation scheme and CPS structure adopted from other sectors and termed as cyberphysical production system (CPPS). All the technology modules, like human-robot collaboration, connected CPPS physical elements, smart devices and raw-materials, big data 
analytics, and real-time intelligent decision-making using artificial intelligence and cyber security, are becoming basic ingredients for the food manufacturing CPS or CPFPS (Fig. 3). Technology transfer of solutions developed and tested in other industries can enhance the overall digitalization of records and create a joined system for tracking and traceability. For example, application of developments in medical sphere for electronic records [25, 49] or blockchain approaches can generate enormous benefits for traceability, efficiency, and sustainability analysis of food systems at larger scale [6,99].

The second application area (2) pertains to the CPS in food manufacturing and serving industry in the futuristic industry 4.0 era. In such system, food production, ordering, preparation, and serving functions exist simultaneously in close premises. This has the potential to exhibit human-robot collaboration in the cyber physical food serving system (CPFSS) model on both ends of the robotic serving process or may confine to the customer end in the future [69]. Moreover, common current connection between CPFPS and CPFSS is highlighted to be the compulsory inclusion of the human-cyber systems interactions [83]. Such approaches can easily integrate the requirements for the personalized retail and nutrition and nudge it to the implementation [17]. Both approaches indicate the need to integrate already developed and upcoming technological solutions in the food system. While being feasible, they still do not indicate how the cyber systems will be connected with the second physical level (Fig. 4) and more specifically its biomass sub-level.

We see the integration of biomass properties and cyber system as urgent requirement which should be solved before it is possible to create fully functioning food CPS- a system integrating physical environment and food biomass with computer-based system able to deal with food system organization in autonomous and self-manageable manner. While there are some examples of CPS systems integrating cyber and physical level I and even level II (packaging, sensors), no real examples exist, which would be connecting food biomass with the cyber system. Existing approaches can trace and record environmental changes around the biomass mostly [25, 40, 70], but not the change of biomass composition, structure, functional properties, or origin. At the same time, there are specific developments combining the marking and/or tracking of biomass properties directly $[29,48,51,62,66,102,115$, 118], which can enhance the food CPS systems in the future. Such developments can be performed only by the joined effort of food and computer system scientists and developers. Conceptual requirements for food CPS, therefore, should integrate not only cyber parts of the different systems (having different protocols and managed by different actors), but also further development of physical systems (sensors and biomass interaction).

\section{Conclusions}

Despite more than 50 years of CPS research and development, it remains in conceptual stage when it comes to biomass production, food processing, engineering, and consumption. Food value chains as higher hierarchical level system remain uncovered by CPS development. While CPSs are well developed in multiple spheres (automotive, manufacturing, medicine, etc.), their application in food industry is very limited due to lacking of few conceptual challenges: unification and generalization of approached in different food production areas; connection of cyber parts of food chains agents via adapted record-tracking systems (potentially blockchainbased); integration of computational component with chemical and physical properties of food biomass and transfer of such integration though supply chains; and development of efficient defence mechanisms, able to coop with potential cyber-food-safety risks and hazards. Such challenges are becoming the basis for the guidelines of food engineering, production, and consumption system structuring as cyberphysical systems. The conceptual guidelines, indicated in this work, included transfer of successful approaches for computational solutions from fields dealing with similar problems/ systems (medicine, agriculture); creation of multi-hierarchical cyber and physical components, which should solve the problem of transferability and safety; and development of physical-based solutions for the physical-physical system interaction between sensors and food biomass.

Funding Information Open Access funding provided by Projekt DEAL.

Open Access This article is licensed under a Creative Commons Attribution 4.0 International License, which permits use, sharing, adaptation, distribution and reproduction in any medium or format, as long as you give appropriate credit to the original author(s) and the source, provide a link to the Creative Commons licence, and indicate if changes were made. The images or other third party material in this article are included in the article's Creative Commons licence, unless indicated otherwise in a credit line to the material. If material is not included in the article's Creative Commons licence and your intended use is not permitted by statutory regulation or exceeds the permitted use, you will need to obtain permission directly from the copyright holder. To view a copy of this licence, visit http://creativecommons.org/licenses/by/4.0/.

\section{References}

1. Accorsi R, Tufano A, Gallo A, Galizia FG, Cocchi G, Ronzoni M, Abbate A, Manzini R (2019) An application of collaborative robots in a food production facility. Procedia Manuf 38:341-348. https://doi.org/10.1016/j.promfg.2020.01.044

2. Aiello LC, Wheeler P (1995) The expensive-tissue hypothesis: the brain and the digestive system in human and primate evolution. Curr Anthropol 36:199-221. https://doi.org/10.1086/204350

3. Alguliyev R, Imamverdiyev Y, Sukhostat L (2018) Cyberphysical systems and their security issues. Comput Ind 100:212223. https://doi.org/10.1016/j.compind.2018.04.017 
4. An W, Wu D, Ci S et al (2017) Agriculture cyber-physical systems. In: Cyber-physical systems. Elsevier, pp 399-417

5. Anil A, Gupta H, Arora M (2019) Computer vision based method for identification of freshness in mushrooms. In: 2019 International Conference on Issues and Challenges in Intelligent Computing Techniques (ICICT). IEEE, pp 1-4

6. Antonucci F, Figorilli S, Costa C, Pallottino F, Raso L, Menesatti $P$ (2019) A review on blockchain applications in the agri-food sector. J Sci Food Agric 99:6129-6138. https://doi.org/10.1002/ jsfa.9912

7. Asgari S, Sahari MA, Barzegar M (2017) Practical modeling and optimization of ultrasound-assisted bleaching of olive oil using hybrid artificial neural network-genetic algorithm technique. Comput Electron Agric 140:422-432. https://doi.org/10.1016/j. compag.2017.06.025

8. Baheti R, Gill H (2011) Cyber-physical systems. Impact Control Technol 12:161-166

9. Baire M, Melis A, BrunoLodi M, et al (2018) Study and Design of a wireless sensors network for the optimization of bread manufacturing process. In: 2018 26th Telecommunications Forum (TELFOR). IEEE, pp 1-4

10. Banga JR, Balsa-Canto E, Alonso AA (2008) Quality and safety models and optimization as part of computer-integrated manufacturing. Compr Rev Food Sci Food Saf 7:168-174. https://doi.org/10.1111/j.1541-4337.2007.00023.x

11. Barbosa-Cánovas GV, Tapia MS, Cano MP (2004) Novel food processing technologies. CRC press

12. Barr A, Feigenbaum EA (eds) (1981) The handbook of artificial intelligence. Elsevier

13. Berntsen J, Thomsen A, Schelde K, Hansen OM, Knudsen L, Broge N, Hougaard H, Hørfarter R (2006) Algorithms for sensor-based redistribution of nitrogen fertilizer in winter wheat. Precis Agric 7:65-83. https://doi.org/10.1007/s11119-006-9000-2

14. Bettenhausen KD, Kowalewski S (2013) Cyber-physical systems: Chancen und Nutzen aus Sicht der automation. VDI/VDEGesellschaft Mess-und Autom 9-10

15. Bogataj D, Bogataj M, Hudoklin D (2017) Mitigating risks of perishable products in the cyber-physical systems based on the extended MRP model. Int J Prod Econ 193:51-62. https://doi. org/10.1016/j.ijpe.2017.06.028

16. Bordel B, Alcarria R, Robles T, Martín D (2017) Cyber-physical systems: extending pervasive sensing from control theory to the Internet of Things. Pervasive Mob Comput 40:156-184. https:// doi.org/10.1016/j.pmcj.2017.06.011

17. Bornkessel S, Smetana S, Heinz V (2019) Nutritional sustainability inside-marketing sustainability as an inherent ingredient. Front Nutr 6. https://doi.org/10.3389/fnut.2019.00084

18. Boschert S, Rosen R (2016) Digital twin - the simulation aspect. In: Mechatronic futures. Springer International Publishing, Cham, pp 59-74

19. Braun T, Fung BCM, Iqbal F, Shah B (2018) Security and privacy challenges in smart cities. Sustain Cities Soc 39:499-507. https:// doi.org/10.1016/j.scs.2018.02.039

20. Brewster C, Roussaki I, Kalatzis N, Doolin K, Ellis K (2017) IoT in agriculture: designing a Europe-wide large-scale pilot. IEEE Commun Mag 55:26-33. https://doi.org/10.1109/MCOM.2017. 1600528

21. Buche P, Cuq B, Fortin J, Sipieter C (2019) Expertise-based decision support for managing food quality in agri-food companies. Comput Electron Agric 163:104843. https://doi.org/10.1016/j. compag.2019.05.052

22. Burg A, Chattopadhyay A, Lam K-Y (2018) Wireless communication and security issues for cyber-physical systems and the internet-of-things. Proc IEEE 106:38-60. https://doi.org/10.1109/ JPROC.2017.2780172
23. Castelluccia C, Francillon A, Perito D, Soriente C (2009) On the difficulty of software-based attestation of embedded devices. In: Proceedings of the 16th ACM conference on computer and communications security - CCS '09. ACM Press, New York, p 400

24. Chaurasia P, Younis K, Qadri OS, Srivastava G, Osama K (2019) Comparison of Gaussian process regression, artificial neural network, and response surface methodology modeling approaches for predicting drying time of mosambi ( Citrus limetta ) peel. J Food Process Eng 42:e12966. https://doi.org/10.1111/jfpe.12966

25. Chen R-Y (2017) An intelligent value stream-based approach to collaboration of food traceability cyber physical system by fog computing. Food Control 71:124-136. https://doi.org/10.1016/j. foodcont.2016.06.042

26. Chen R-Y (2018) Intelligent predictive food traceability cyber physical system in agriculture food supply chain. J Phys Conf Ser 1026:012017. https://doi.org/10.1088/1742-6596/1026/1/ 012017

27. Chen M-J, Chen K-N, Lin C-W (2006) Sequential quadratic programming for development of a new probiotic dairy tofu with Glucono- $\delta$-lactone. J Food Sci 69:344-350. https://doi.org/10. 1111/j.1365-2621.2004.tb13640.x

28. Chowhan RS, Dayya P (2019) Sustainable smart farming for masses using modern ways of internet of things (IoT) into agriculture. In: Smart devices, applications, and protocols for the IoT. IGI Global, pp 189-219

29. Chyan Y, Ye R, Li Y, Singh SP, Arnusch CJ, Tour JM (2018) Laser-induced graphene by multiple lasing: toward electronics on cloth, paper, and food. ACS Nano 12:2176-2183. https://doi.org/ 10.1021/acsnano.7b08539

30. Creydt M, Fischer M (2019) Blockchain and more - algorithm driven food traceability. Food Control 105:45-51. https://doi. org/10.1016/j.foodcont.2019.05.019

31. Da Xu L, Duan L (2019) Big data for cyber physical systems in industry 4.0: a survey. Enterp Inf Syst 13:148-169. https://doi.org/ 10.1080/17517575.2018.1442934

32. Dallasega P, Rauch E, Linder C (2018) Industry 4.0 as an enabler of proximity for construction supply chains: a systematic literature review. Comput Ind 99:205-225. https://doi.org/10.1016/j. compind.2018.03.039

33. Darwish A, Hassanien AE (2018) Cyber physical systems design, methodology, and integration: the current status and future outlook. J Ambient Intell Humaniz Comput 9:1541-1556. https://doi. org/10.1007/s12652-017-0575-4

34. Deb K, Pratap A, Agarwal S, Meyarivan T (2002) A fast and elitist multiobjective genetic algorithm: NSGA-II. IEEE Trans Evol Comput 6:182-197. https://doi.org/10.1109/4235.996017

35. Defraeye T (2014) Advanced computational modelling for drying processes - a review. Appl Energy 131:323-344. https://doi.org/ 10.1016/j.apenergy.2014.06.027

36. Delgado JA, Short NM, Roberts DP, Vandenberg B (2019) Big data analysis for sustainable agriculture on a geospatial cloud framework. Front Sustain Food Syst 3. https://doi.org/10.3389/ fsufs. 2019.00054

37. Deng X, Zhang J (2020) Multi-objective location of fresh food ecommerce distribution network based on improved NSGA-II algorithm. In: ICTE 2019. American Society of Civil Engineers, Reston, pp 671-680

38. Deng S, Xu Y, Li L, Li X, He Y (2013) A feature-selection algorithm based on support vector machine-multiclass for hyperspectral visible spectral analysis. J Food Eng 119:159-166. https://doi.org/10.1016/j.jfoodeng.2013.05.024

39. Fang Z, Zhao Y, Warner RD, Johnson SK (2017) Active and intelligent packaging in meat industry. Trends Food Sci Technol 61:60-71. https://doi.org/10.1016/j.tifs.2017.01.002

40. Feng Tian (2017) A supply chain traceability system for food safety based on HACCP, blockchain \&amp; Internet of things. 
In: 2017 International Conference on Service Systems and Service Management. IEEE, pp 1-6

41. Ferrández MR, Puertas-Martín S, Redondo JL, Ivorra B, Ramos AM, Ortigosa PM (2019a) High-performance computing for the optimization of high-pressure thermal treatments in food industry. J Supercomput 75:1187-1202. https://doi.org/10.1007/s11227018-2351-4

42. Ferrández MR, Redondo JL, Ivorra B, Ramos ÁM, Ortigosa PM (2019b) Preference-based multi-objectivization applied to decision support for high-pressure thermal processes in food treatment. Appl Soft Comput 79:326-340. https://doi.org/10.1016/j. asoc.2019.03.050

43. Galvez JF, Mejuto JC, Simal-Gandara J (2018) Future challenges on the use of blockchain for food traceability analysis. TrAC Trends Anal Chem 107:222-232. https://doi.org/10.1016/ j.trac.2018.08.011

44. Ghasemi-Varnamkhasti M, Mohammad-Razdari A, Yoosefian SH, Izadi Z, Siadat M (2019) Aging discrimination of French cheese types based on the optimization of an electronic nose using multivariate computational approaches combined with response surface method (RSM). LWT 111:85-98. https://doi.org/10. 1016/j.lwt.2019.04.099

45. Gill SS, Chana I, Buyya R (2017) IoT based agriculture as a cloud and big data service. J Organ End User Comput 29:1-23. https:// doi.org/10.4018/JOEUC.2017100101

46. Gunes V, Peter S, Givargis T, Vahid F (2014) A survey on concepts, applications, and challenges in cyber-physical systems. KSII Trans Internet Inf Syst 8. https://doi.org/10.3837/tiis.2014. 12.001

47. Guo P, Dusadeerungsikul PO, Nof SY (2018) Agricultural cyber physical system collaboration for greenhouse stress management. Comput Electron Agric 150:439-454. https://doi.org/10.1016/j. compag.2018.05.022

48. Hamilton CA, Alici G, in het Panhuis M (2018) 3D printing vegemite and marmite: redefining "breadboards". J Food Eng 220:83-88. https://doi.org/10.1016/j.jfoodeng.2017.01.008

49. Haque SA, Aziz SM, Rahman M (2014) Review of cyber-physical system in healthcare. Int J Distrib Sens Networks 10:217415. https://doi.org/10.1155/2014/217415

50. Hardie M, Hoyle D (2019) Underground wireless data transmission using 433-MHz LoRa for agriculture. Sensors 19:4232. https://doi.org/10.3390/s19194232

51. Henze N, Olsson T, Schneegass S et al (2015) Augmenting food with information. In: Proceedings of the 14th international conference on mobile and ubiquitous multimedia - MUM '15. ACM Press, New York, pp 258-266

52. Humayed A, Lin J, Li F, Luo B (2017) Cyber-physical systems security-a survey. IEEE Internet Things J 4:1802-1831. https:// doi.org/10.1109/JIOT.2017.2703172

53. Hwang C, Mo C, Kim G, Kim MS (2019) Detection of produce residues on processing equipment surfaces using fluorescence imaging. In: Kim MS, Cho B-K, Chin BA (eds) Sensing for Agriculture and Food Quality and Safety XI. SPIE, p 23

54. Iqbal J, Khan ZH, Khalid A (2017) Prospects of robotics in food industry. Food Sci Technol 37:159-165. https://doi.org/10.1590/ 1678-457x.14616

55. Joardder MUH, Kumar C, Karim MA (2017) Food structure: its formation and relationships with other properties. Crit Rev Food Sci Nutr 57:1190-1205. https://doi.org/10.1080/10408398.2014. 971354

56. Junge K, Hughes J, Thuruthel TG, Iida F (2020) Improving robotic cooking using batch Bayesian optimization. IEEE Robot Autom Lett 5:760-765. https://doi.org/10.1109/LRA.2020.2965418

57. Kalpana S, Priyadarshini SR, Maria Leena M, Moses JA, Anandharamakrishnan C (2019) Intelligent packaging: trends and applications in food systems. Trends Food Sci Technol 93: 145-157. https://doi.org/10.1016/j.tifs.2019.09.008

58. Khalilpourazari S, Khalilpourazary S (2018) Optimization of time, cost and surface roughness in grinding process using a robust multi-objective dragonfly algorithm. Neural Comput Appl 32: 3987-3998. https://doi.org/10.1007/s00521-018-3872-8

59. Khan ZH, Khalid A, Iqbal J (2018) Towards realizing robotic potential in future intelligent food manufacturing systems. Innov Food Sci Emerg Technol 48:11-24. https://doi.org/10.1016/j.ifset. 2018.05.011

60. Khoa TA, Man MM, Nguyen T-Y, Nguyen VD, Nam NH (2019) Smart agriculture using IoT multi-sensors: a novel watering management system. J Sens Actuator Networks 8:45. https://doi.org/ $10.3390 /$ jsan 8030045

61. Kim K-D, Kumar PR (2012) Cyber-physical systems: a perspective at the centennial. Proc IEEE 100:1287-1308. https://doi.org/ 10.1109/JPROC.2012.2189792

62. Kim J, Jeerapan I, Ciui B, Hartel MC, Martin A, Wang J (2017) Edible electrochemistry: food materials based electrochemical sensors. Adv Healthc Mater 6:1700770. https://doi.org/10.1002/ adhm. 201700770

63. Knorr D, Froehling A, Jaeger H, Reineke K, Schlueter O, Schoessler K (2011) Emerging technologies in food processing. Annu Rev Food Sci Technol 2:203-235. https://doi.org/10.1146/ annurev.food.102308.124129

64. Kochhar A, Kumar N (2019) Wireless sensor networks for greenhouses: an end-to-end review. Comput Electron Agric 163: 104877. https://doi.org/10.1016/j.compag.2019.104877

65. Kumar SA, Ilango P (2018) The impact of wireless sensor network in the field of precision agriculture: a review. Wirel Pers Commun 98:685-698. https://doi.org/10.1007/s11277-017-4890-z

66. Lanzani G (2014) Organic electronics meets biology. Nat Mater 13:775-776. https://doi.org/10.1038/nmat4021

67. Lee J, Lapira E, Bagheri B, Kao H (2013) Recent advances and trends in predictive manufacturing systems in big data environment. Manuf Lett 1:38-41. https://doi.org/10.1016/j.mfglet.2013. 09.005

68. Lee J, Bagheri B, Kao H-A (2015) A cyber-physical systems architecture for industry 4.0-based manufacturing systems. Manuf Lett 3:18-23. https://doi.org/10.1016/j.mfglet.2014.12. 001

69. Leung Pah Hang MY, Martinez-Hernandez E, Leach M, Yang A (2016) Designing integrated local production systems: a study on the food-energy-water nexus. J Clean Prod 135:1065-1084. https://doi.org/10.1016/j.jclepro.2016.06.194

70. Li Z, Liu G, Liu L, Lai X, Xu G (2017) IoT-based tracking and tracing platform for prepackaged food supply chain. Ind Manag Data Syst 117:1906-1916. https://doi.org/10.1108/IMDS-112016-0489

71. Liegeard J, Manning L (2020) Use of intelligent applications to reduce household food waste. Crit Rev Food Sci Nutr 60:1048 1061. https://doi.org/10.1080/10408398.2018.1556580

72. Liu R, Zhang Y, Ge Y, Hu W, Sha B (2020) Precision regulation model of water and fertilizer for alfalfa based on agriculture cyberphysical system. IEEE Access 8:38501-38516. https://doi.org/10. 1109/ACCESS.2020.2975672

73. Lopes JF, Ludwig L, Barbin DF, Grossmann MVE, Barbon S Jr (2019) Computer vision classification of barley flour based on spatial pyramid partition ensemble. Sensors 19:2953. https://doi. org/10.3390/s19132953

74. Luo S, Jin JS, Li J (2009) A smart fridge with an ability to enhance health and enable better nutrition. Int J Multimed Ubiquitous Eng 4:69-80

75. Marwedel P (2018) Embedded system design. Springer International Publishing, Cham 
76. Monostori L, Kádár B, Bauernhansl T, Kondoh S, Kumara S, Reinhart G, Sauer O, Schuh G, Sihn W, Ueda K (2016) Cyberphysical systems in manufacturing. CIRP Ann 65:621-641. https://doi.org/10.1016/j.cirp.2016.06.005

77. Moreno G, Kinneer C, Pandey A, Garlan D (2019) DARTSim: An exemplar for evaluation and comparison of self-adaptation approaches for smart cyber-physical systems. In: 2019 IEEE/ ACM 14th International Symposium on Software Engineering for Adaptive and Self-Managing Systems (SEAMS). IEEE, pp 181-187

78. Mosterman PJ, Zander J (2016) Industry 4.0 as a cyber-physical system study. Softw Syst Model 15:17-29. https://doi.org/10. 1007/s10270-015-0493-X

79. Müller P, Schmid M (2019) Intelligent packaging in the food sector: a brief overview. Foods 8:16. https://doi.org/10.3390/ foods 8010016

80. Neugebauer R, Denkena B, Wegener K (2007) Mechatronic systems for machine tools. CIRP Ann 56:657-686. https://doi.org/10. 1016/j.cirp.2007.10.007

81. Pandey G, Weber RJ, Kumar R (2018) Agricultural cyberphysical system: in-situ soil moisture and salinity estimation by dielectric mixing. IEEE Access 6:43179-43191. https://doi.org/ 10.1109/ACCESS.2018.2862634

82. Perrot N, De Vries H, Lutton E et al (2016) Some remarks on computational approaches towards sustainable complex agrifood systems. Trends Food Sci Technol 48:88-101. https://doi. org/10.1016/j.tifs.2015.10.003

83. Pirvu B-C, Zamfirescu C-B, Gorecky D (2016) Engineering insights from an anthropocentric cyber-physical system: a case study for an assembly station. Mechatronics 34:147-159. https://doi. org/10.1016/j.mechatronics.2015.08.010

84. Poovendran R (2010) Cyber-physical systems: close encounters between two parallel worlds [point of view]. Proc IEEE 98:13631366. https://doi.org/10.1109/JPROC.2010.2050377

85. Poyatos-Racionero E, Ros-Lis JV, Vivancos J-L, Martínez-Máñez $R$ (2018) Recent advances on intelligent packaging as tools to reduce food waste. J Clean Prod 172:3398-3409. https://doi.org/ 10.1016/j.jclepro.2017.11.075

86. Priyadarshini A, Rajauria G, O'Donnell CP, Tiwari BK (2019) Emerging food processing technologies and factors impacting their industrial adoption. Crit Rev Food Sci Nutr 59:3082-3101. https://doi.org/10.1080/10408398.2018.1483890

87. Provost F, Fawcett T (2013) Data science and its relationship to big data and data-driven decision making. Big Data 1:51-59. https://doi.org/10.1089/big.2013.1508

88. Qi Q, Tao F (2018) Digital twin and big data towards smart manufacturing and industry 4.0: 360 degree comparison. IEEE Access 6:3585-3593. https://doi.org/10.1109/ACCESS.2018. 2793265

89. Rad C-R, Hancu O, Takacs I-A, Olteanu G (2015) Smart monitoring of potato crop: a cyber-physical system architecture model in the field of precision agriculture. Agric Agric Sci Procedia 6: 73-79. https://doi.org/10.1016/j.aaspro.2015.08.041

90. Rajkumar R, Lee I, Sha L, Stankovic J (2010) Cyber-physical systems. In: proceedings of the 47th design automation conference on - DAC '10. ACM Press, New York, p 731

91. Režek Jambrak A, Donsì F, Paniwnyk L, Djekic I (2019) Impact of novel nonthermal processing on food quality: sustainability, modelling, and negative aspects. J Food Qual 2019:1-2. https:// doi.org/10.1155/2019/2171375

92. Romdhana H, Bonazzi C, Esteban-Decloux M (2016) Computeraided process engineering for environmental efficiency: industrial drying of biomass. Dry Technol 34:1253-1269. https://doi.org/10. 1080/07373937.2015.1104348

93. Selmani A, Oubehar H, Outanoute M, Ed-Dahhak A, Guerbaoui M, Lachhab A, Bouchikhi B (2019) Agricultural cyber-physical system enabled for remote management of solar-powered precision irrigation. Biosyst Eng 177:18-30. https://doi.org/10.1016/j. biosystemseng.2018.06.007

94. Shi X, An X, Zhao Q, Liu H, Xia L, Sun X, Guo Y (2019) Stateof-the-art internet of things in protected agriculture. Sensors 19: 1833. https://doi.org/10.3390/s19081833

95. Shukla N, Tiwari MK, Beydoun G (2019) Next generation smart manufacturing and service systems using big data analytics. Comput Ind Eng 128:905-910. https://doi.org/10.1016/j.cie. 2018.12.026

96. Silva AR, Vuran MC (2010) (CPS)^2: integration of center pivot systems with wireless underground sensor networks for autonomous precision agriculture. In: Proceedings of the 1st ACM/IEEE International Conference on Cyber-Physical Systems - ICCPS ' 10. ACM Press, New York, p 79

97. Silva BN, Diyan M, Han K (2019) Big data analytics. Pp 13-30

98. Smajic H, Wessel N (2018) Remote Control of Large Manufacturing Plants Using Core Elements of Industry 4.0. pp. 546-551

99. Smetana S, Seebold C, Heinz V (2018) Neural network, blockchain, and modular complex system: the evolution of cyber-physical systems for material flow analysis and life cycle assessment. Resour Conserv Recycl 133:229-230. https://doi.org/ 10.1016/j.resconrec.2018.02.020

100. Smetana SM, Bornkessel S, Heinz V (2019) A path from sustainable nutrition to nutritional sustainability of complex food systems. Front Nutr 6. https://doi.org/10.3389/fnut.2019.00039

101. Sundmaeker H, Verdouw C, Wolfert S et al (2016) Internet of food and farm 2020. In: Vermesan O, Friess P (eds) Digitising the industry-internet of things connecting physical, digital and virtual worlds. River Publishers, Gistrup/Delft, pp 129-151

102. Tao H, Brenckle MA, Yang M, Zhang J, Liu M, Siebert SM, Averitt RD, Mannoor MS, McAlpine MC, Rogers JA, Kaplan DL, Omenetto FG (2012) Silk-based conformal, adhesive, edible food sensors. Adv Mater 24:1067-1072. https://doi.org/10.1002/ adma.201103814

103. Tao F, Cheng J, Qi Q, Zhang M, Zhang H, Sui F (2018) Digital twin-driven product design, manufacturing and service with big data. Int J Adv Manuf Technol 94:3563-3576. https://doi.org/10. 1007/s00170-017-0233-1

104. Tao F, Qi Q, Wang L, Nee AYC (2019) Digital twins and cyberphysical systems toward smart manufacturing and industry 4.0 : correlation and comparison. Engineering 5:653-661. https://doi. org/10.1016/j.eng.2019.01.014

105. Thakur D, Kumar Y, Kumar A, Kumar P, Singh V (2018) Real time monitoring of Valeriana Jatamansi plant for growth analysis. Procedia Comput Sci 132:507-517. https://doi.org/10.1016/j. procs.2018.05.003

106. Thomopoulos R, Baudrit C, Boukhelifa N, Boutrou R, Buche P, Guichard E, Guillard V, Lutton E, Mirade PS, Ndiaye A, Perrot N, Taillandier F, Thomas-Danguin T, Tonda A (2019) Multi-criteria reverse engineering for food: genesis and ongoing advances. Food Eng Rev 11:44-60. https://doi.org/10.1007/s12393-018-9186-x

107. Uhlemann TH-J, Lehmann C, Steinhilper R (2017) The digital twin: realizing the cyber-physical production system for industry 4.0. Procedia CIRP 61:335-340. https://doi.org/10.1016/j.procir. 2016.11.152

108. Vanderroost M, Ragaert P, Verwaeren J, de Meulenaer B, de Baets B, Devlieghere F (2017) The digitization of a food package's life cycle: existing and emerging computer systems in the logistics and post-logistics phase. Comput Ind 87:15-30. https:// doi.org/10.1016/j.compind.2017.01.004

109. Verboven P, Defraeye T, Datta AK, Nicolai B (2020) Digital twins of food process operations: the next step for food process models? Curr Opin Food Sci 35:79-87. https://doi.org/10.1016/j. cofs.2020.03.002 
110. Verdouw CN, Beulens AJM, Reijers HA, van der Vorst JGAJ (2015) A control model for object virtualization in supply chain management. Comput Ind 68:116-131. https://doi.org/10.1016/j. compind.2014.12.011

111. Verdouw CN, Wolfert J, Beulens AJM, Rialland A (2016) Virtualization of food supply chains with the internet of things. J Food Eng 176:128-136. https://doi.org/10.1016/j.jfoodeng.2015. 11.009

112. Vuran MC, Salam A, Wong R, Irmak S (2018) Internet of underground things in precision agriculture: architecture and technology aspects. Ad Hoc Netw 81:160-173. https://doi.org/10.1016/j. adhoc.2018.07.017

113. Waller MA, Fawcett SE (2013) Data science, predictive analytics, and big data: a revolution that will transform supply chain design and management. J Bus Logist 34:77-84. https://doi.org/10.1111/ jbl.12010

114. Wang J, Yue H (2017) Food safety pre-warning system based on data mining for a sustainable food supply chain. Food Control 73: 223-229. https://doi.org/10.1016/j.foodcont.2016.09.048

115. Wang X, Xu W, Chatterjee P, Lv C, Popovich J, Song Z, Dai L, Kalani MYS, Haydel SE, Jiang H (2016) Food-materials-based edible supercapacitors. Adv Mater Technol 1:1600059. https:// doi.org/10.1002/admt.201600059

116. Wolfert J, Verdouw CN, Verloop CM, Beulens AJM (2010) Organizing information integration in agri-food - a method based on a service-oriented architecture and living lab approach. Comput Electron Agric 70:389-405. https://doi.org/10.1016/j. compag.2009.07.015

117. Wright $P$ (2014) Cyber-physical product manufacturing. Manuf Lett 2:49-53. https://doi.org/10.1016/j.mfglet.2013.10.001

118. Xu W, Yang H, Zeng W, Houghton T, Wang X, Murthy R, Kim H, Lin Y, Mignolet M, Duan H, Yu H, Slepian M, Jiang H (2017) Food-based edible and nutritive electronics. Adv Mater Technol 2: 1700181. https://doi.org/10.1002/admt.201700181
119. Xu Y, Gao Z, Khot L, Meng X, Zhang Q (2018) A real-time weed mapping and precision herbicide spraying system for row crops. Sensors 18:4245. https://doi.org/10.3390/s18124245

120. Yan B, Yan C, Ke C, Tan X (2016) Information sharing in supply chain of agricultural products based on the internet of things. Ind Manag Data Syst 116:1397-1416. https://doi.org/10.1108/IMDS12-2015-0512

121. Yan J, Zhang M, Fu Z (2019) An intralogistics-oriented cyberphysical system for workshop in the context of industry 4.0 . Procedia Manuf 35:1178-1183. https://doi.org/10.1016/j.promfg. 2019.06.074

122. Yuan J, Wang K, Yu T, Fang M (2008) Reliable multi-objective optimization of high-speed WEDM process based on Gaussian process regression. Int J Mach Tools Manuf 48:47-60. https:// doi.org/10.1016/j.ijmachtools.2007.07.011

123. Zhang W, Zhang Y, Zhai J, Zhao D, Xu L, Zhou J, Li Z, Yang S (2018) Multi-source data fusion using deep learning for smart refrigerators. Comput Ind 95:15-21. https://doi.org/10.1016/j. compind.2017.09.001

124. Zhao X, Fan H, Zhu H et al (2015) The design of the internet of things solution for food supply chain. In: Proceedings of the 2015 International conference on education, management, information and medicine. Atlantis Press, Paris

125. Zhou I, Lipman J, Abolhasan M, Shariati N, Lamb DW (2020) Frost monitoring cyber-physical system: a survey on prediction and active protection methods. IEEE Internet Things J:1. https:// doi.org/10.1109/JIOT.2020.2972936

126. (2019) Development of the World's Network Information Technology. In: World Internet Development Report 2017. Springer Berlin Heidelberg, Berlin, Heidelberg, pp. 55-87

Publisher's Note Springer Nature remains neutral with regard to jurisdictional claims in published maps and institutional affiliations. 